\title{
The Multimedia Challenges Raised by Pervasive Games
}

\author{
Mauricio Capra, Milena Radenkovic, Steve Benford, Leif Oppermann, \\ Adam Drozd, Martin Flintham \\ The University of Nottingham - Mixed Reality Laboratory - Jubilee Campus, Nottingham, UK, NG8 1BB \\ $\{\mathrm{mxc}, \mathrm{mvr}, \mathrm{sdb}$, Ixo, asd, mdf\}@cs.nott.ac.uk
}

\begin{abstract}
Pervasive gaming is a new form of multimedia entertainment that extends the traditional computer gaming experience out into the real world. Through a combination of personal devices, positioning systems and other multimedia sensors, combined with wireless networking, a pervasive game can respond to a player's movements and context and enable them to communicate with a game server and other players. We review recent examples of pervasive games in order to explain their distinctive characteristics as multimedia applications. We then consider the challenge of scaling pervasive games to include potentially very large numbers of players. We propose a new approach based upon a campaign model in which individuals, local groups and experts draw on a combination of pervasive games, online services and broadcasting to take part in national or even global events. We discuss the challenges that this raises for further research.
\end{abstract}

\section{Categories and Subject Descriptors}

H1.2 User/Machine Systems; H5 Information Interfaces and Presentation; C2.4 Distributed Systems.

\section{General Terms}

Design, Human Factors.

\section{Keywords}

Pervasive computing, games, sensors, scalability.

\section{INTRODUCTION}

The rapid spread and continuing development of mobile phones, handheld computers and other personal devices, supported by advances in wireless networking and positioning and sensing systems, has given rise to pervasive computing in which multimedia information is embedded into the physical world around us and accessed via location-based services. Potential application domains for pervasive computing include the workplace [1, 2] tourism [3], information retrieval [4], network routing and resource discovery [5], learning [6] and games [7].

In this paper, we review some early examples of pervasive applications, focusing on games in particular, in order to highlight

Permission to make digital or hard copies of all or part of this work for personal or classroom use is granted without fee provided that copies are not made or distributed for profit or commercial advantage and that copies bear this notice and the full citation on the first page. To copy otherwise, or republish, to post on servers or to redistribute to lists, requires prior specific permission and/or a fee.

$M M^{\prime} 05$, November 6-11, 2005, Singapore.

Copyright 2005 ACM 1-59593-044-2/05/0011_..\$5.00. their distinctive characteristics. We then consider the challenge of scale - how can we create new kinds of mass participation pervasive games that build on the phenomenal popularity of mobile phones? In response, we propose a new approach based on the idea of national or even global 'campaigns' which in turn raises new challenges for multimedia research.

\section{PERVASIVE GAMES}

The physical world is an unbeatable source of information, supplying us at each moment with a continual stream of new images, sounds and feelings that cannot be fully simulated by computers. Pervasive games aim to directly exploit the richness of the physical world as a resource for play by interweaving digital media with our everyday experience. Sensors capture information about a player's current context, including their location, and this is used to deliver them a gaming experience that changes according to where they are, what they are doing, and potentially, even how they are feeling.

There are several approaches to creating pervasive games including reinterpreting classic computer games, mapping them into the physical world so that players have to physically run about in order to control their avatars, as demonstrated by the ARQuake project [8]. Other examples focus strongly on the social nature of mobile interaction and gameplay, for example the STARS platform for augmented tabletop games that preserves the rich social interaction found in traditional board and tabletop games [7]. Yet others take established physical games including treasure hunts and team challenges and augment them with mobile communications, often as a way of coordinating players [9-11]. It is perhaps easiest to appreciate the distinctive characteristics and ultimate potential of pervasive games by briefly reviewing some of recent examples.

\subsection{Can You See Me Now?}

Created by the artists group Blast Theory $[12,13]$ in collaboration with the Mixed Reality Laboratory, Can You See Me Now? (CYSMN) is a game of chase in which online players who are logged in over the Internet are chased through a $3 \mathrm{D}$ model of a virtual city by 'street players' who, equipped with handheld computers, GPS, camcorders and WiFi, have to run through the actual city streets trying to catch them. The game has toured to cities in Europe and Asia, including Sheffield, Cologne, Oldenberg, Barcelona, Cambridge, Brighton and Tokyo, and was awarded the 2003 Prix Ars Electronica Golden Nica for Interactive Art.

CYSMN focuses on rich interaction between online and street players. As a chase game, up to twenty online players are hunted by three street players, professional performers from Blast Theory, on the streets of a real city. Street players are equipped with 
handheld computers, GPS receivers, digital cameras and walkietalkies and are connected to the game through a wireless network (using 802.11b). They play the game using an electronic map that shows the locations of online players and also other street players, the latter reported by GPS. They move their own avatar across this map by running through the actual city streets, and if this avatar gets to within five virtual meters of an online player's avatar then that online player is deemed to be caught.

As they run, the street players discuss their tactics and experience over a walkie-talkie channel and this is encoded and streamed live to the online players who can therefore 'tune in' to a remote street player's experience of the city and adjust their tactics accordingly, for example crossing empty virtual roads in order to cause them to negotiate real traffic or leading them up hills. Finally, whenever a street player catches an online player they take their photograph (actually, a photograph of the location where they were caught) which is subsequently uploaded onto the game website.

Figure 1 shows a street player and their equipment. Figure 2 shows the online interface, where the black avatar is an online player and the avatar surrounded by a red sphere is a street player.

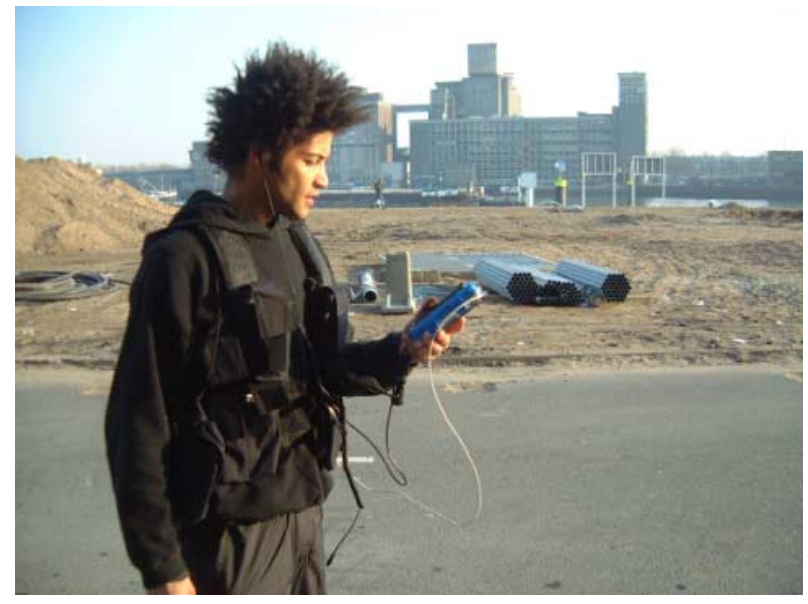

Figure 1. A Street player in CYSMN.

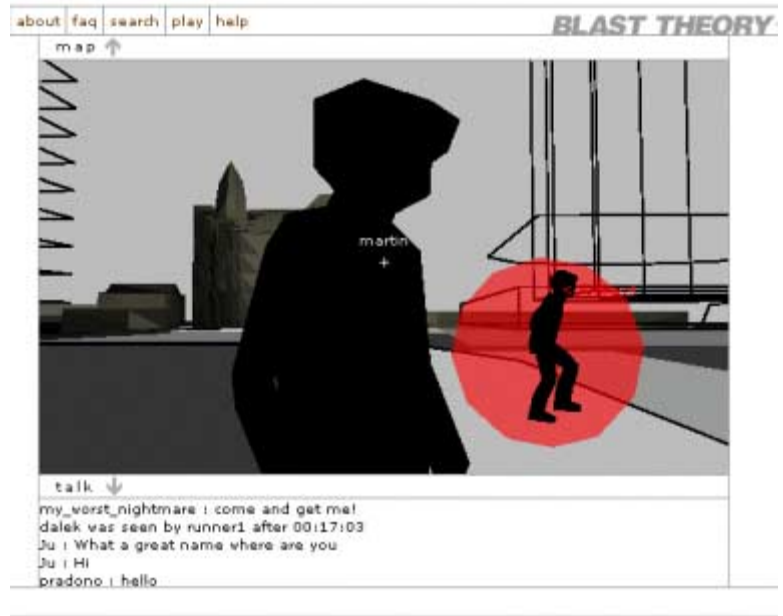

Figure 2. The online interface in CYSMN.
On the bottom of the figure is the text area where online players can communicate with each other and can also send text messages to the street players.

Studies of CYSMN as it toured have revealed key issues for the design and deployment of pervasive games including the considerable impact of uncertainty due to limited GPS coverage and accuracy and limited WiFi coverage on both online and street players. This has led to new proposals for how to deal with uncertainty in pervasive games including removing it, hiding it, managing it, revealing it and even exploiting it [12].

\subsection{Uncle Roy All Around You}

Also developed by Blast Theory and The Mixed Reality Laboratory, Uncle Roy All Around You mixes street players who journey through a city in search of an elusive character called Uncle Roy, with online players who journey through a parallel 3D model of the same city, are able to follow the progress of street players, can communicate with them and can choose to help or hinder them [14]. The core artistic theme of the work is trust in strangers - be they remote players, Uncle Roy or even passersby on the city streets.

Street players purchase a ticket for an experience that will last for a maximum of one hour. On arrival at the hosting venue they hand over all of their personal possessions including bags, wallets, mobile phones and keys, in exchange for a handheld computer, a ritual that is intended to increase their sense of anticipation, vulnerability, dependence on Uncle Roy and isolation and disconnection from the everyday experience of the city. An actor briefs them that their mission is to rendezvous with Uncle Roy and explains how to use the handheld computer. They then head out into the city and enter a nearby park.

Their first task is to find a red marker on their electronic map, to get to the physical location that this indicates, and then to declare their position to Uncle Roy. In return, they receive a short text message back from Uncle Roy that provides them with a clue as to where to go next. In this way, the street players begin a journey through the city, following a trail of often ambiguous and sometimes even mischievously misleading clues that lead them through the park and into the narrow city streets in search of their ultimate goal - Uncle Roy's office. Eventually most street players find their way to the office door within their allotted time. They then enter the final phase of the game where they explore the office and from there are led to a waiting limousine where they encounter a live actor who asks them questions about trust in strangers and invites them to commit to a year long contract to potentially help another player who is somewhere in the game.

An online player, connected to the game over the Internet, journeys through a parallel 3D model of the game space. They move their avatar through this model using the arrow keys on their keyboard, encounter other online players and send them public text messages. Online players also access a set of cards that provide details of the current street players in the game, including their name, gender, a brief description and a photograph that was taken when they registered to play. Street players' reported positions on the actual city streets are represented in the virtual city model so that online players can follow their progress. They can choose to send private text messages to individual street players or listen to their most recently uploaded audio message. 
Online players find photo objects as they explore the model. Entering these triggers the display of photographs from the actual city streets at this location, one of which is labelled as Uncle Roy's office and shows an image of his distinctive office door. In this way, online players can find out useful information to guide street players. Finally, whenever a street player enters Uncle Roy's office, online players are invited to join them. This involves seeing a live webcam view looking into the office which enables them to see the street player in person for the first time. At this point they too are questioned about their trust in strangers and are invited to enter a year long contract to help another player in the game. After the game, those street and online players who agreed to enter such a contract are paired off and sent each others contact details.

Figure 3 shows a street player and figure 4 shows the online interface, including an image of the virtual city model, a card giving details of a street player and the text chat area.

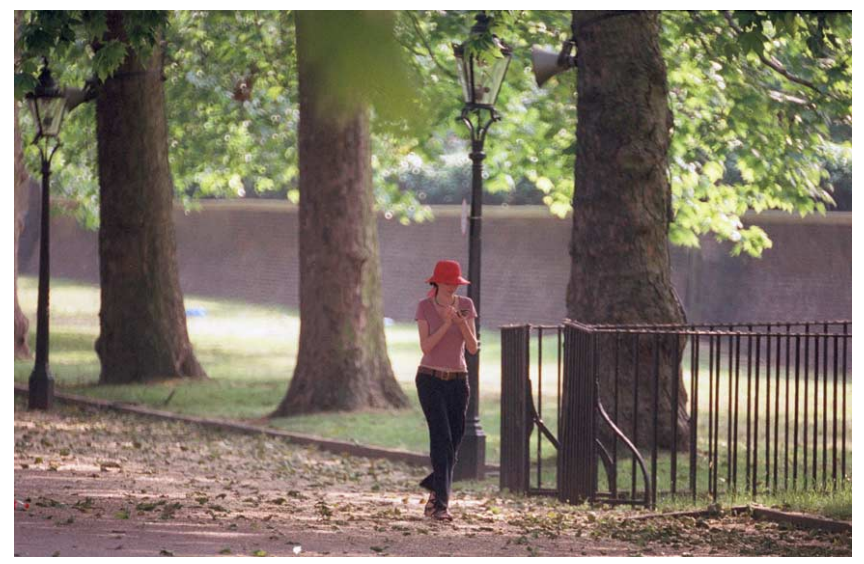

Figure 3. A street player in Uncle Roy All Around You.

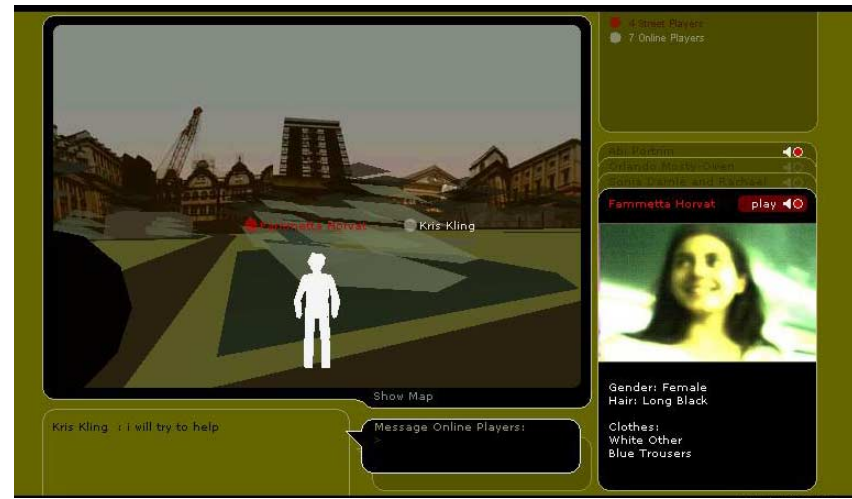

Figure 4. The online interface in Uncle Roy All Around You.

The development and support of Uncle Roy All Around You as it toured drove the design of new authoring tools for pervasive games, including the approach of artists directly colouring over maps to flexibly, rapidly and iterative author content; new interfaces for orchestrating live events, monitoring players' experiences and intervening from behind the scenes when necessary; and also refining the approach of self-reported positioning in which players declare their own positions to the game through their use of an electronic map [15].

\subsection{Savannah}

Savannah is an educational game developed by NESTA Futurelab, Hewlett-Packard Laboratories, The BBC and the Universities of Nottingham and Bristol in which children learn about the ecology of the African savannah, specifically about lion behaviour [6, 16]. Groups of six children at a time role play being lions by exploring a virtual savannah that appears to be overlaid on an empty school playing field, an open grassy area of roughly ninety by sixty meters. Equipped with handheld computers with WiFi networking and GPS, the children move around the playing field, exploring the varied terrain of the savannah and discovering the resources that lions need to survive.

The game requires collaboration; just as a pride of lions has to work together to survive, so users have to work together to win the game by first scouting for resources, and then in later levels by deciding which animals to attack and how many lions must attack together at the same location in order to succeed. For example, a lone lion can bring down a stray calf, whereas several lions are needed to bring down a mature buffalo, and even all six lions will not bring down a full-grown elephant.

Figure 5 shows two lions playing the game with a typical image from the game inset that shows an animal that they have encountered in this particular region of the playing field, along with option to attack it and an indication of their hunger status.

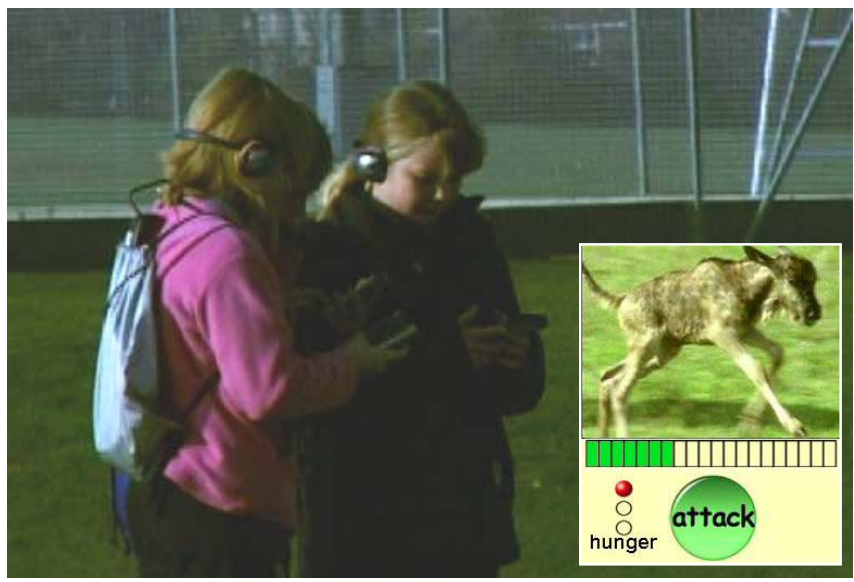

Figure 5. 'Lions' hunting for food as part of the Savannah location-based education game.

Savannah also includes a Den, an area of the classroom to which the players retire after a level and where they use a smart-board to replay a system recording of their actions so that they can reflect on how they performed. A system recording is essentially a log of time-stamped events as seen from the system perspective that allows the experience to be recreated as if it were live.

Figure 6 shows the Den interface. To its left we see a birds eye view of the virtual savannah with the different territories and positions of the players marked. To the right we see a summary of each player's status. At the bottom we see controls for scrolling backwards and forwards through the recording, including skipping on to the next significant event (e.g., an attack). Studies of Savannah suggest that this approach of moving between periods of physically active play in the field and more contemplative reflection back indoors may be important for effective learning. 


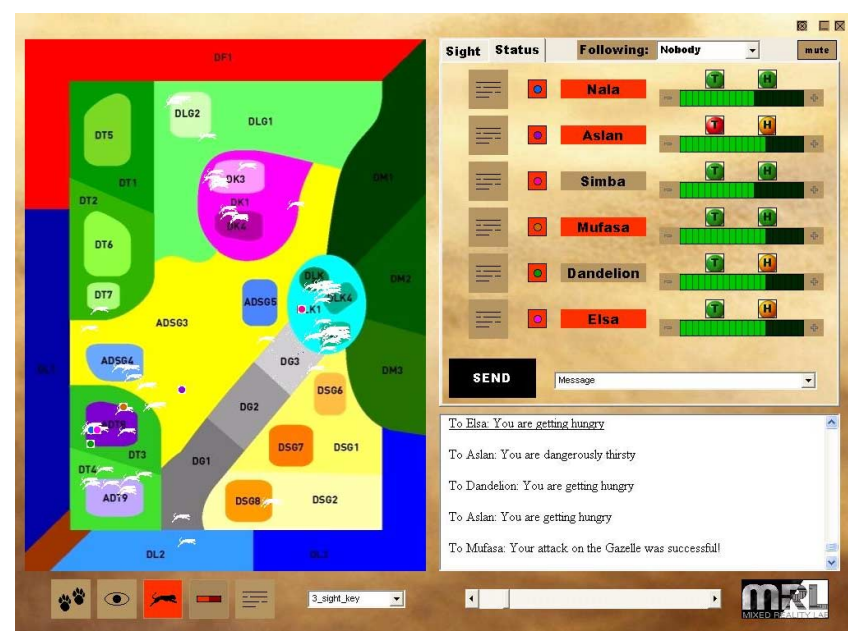

Figure 6. The Den Interface in Savannah.

These three examples illustrate some of the key features and challenges that are distinctive for pervasive games.

- Mobility: players move over potentially large physical areas and make extensive use of multimedia enabled mobile devices, often enhanced with positioning and wireless communications. Challenges that are concerned with the particular characteristics of mobility include designing multimedia interfaces for small devices and dealing with frequent disconnection, limited coverage and uncertain positioning as revealed by studies of all three experiences.

- Interacting in public: a great deal of the excitement of experiences such as Uncle Roy All Around You emerges from the way in which it draws on and implicates the surrounding city and its inhabitants in the game to generate a compelling sense of mystery. However, creating games that mingle players and bystanders also raises significant challenges. How are bystanders to understand players interactions and behaviour and need they even be aware that a game is taking place? Conversely, what are the risks to players of engaging with people and structures that are not directly part of the game or under control of the game masters? How can advances in pervasive multimedia infrastructures influence this?

- Location specific: these games are tied into particular locations, drawing extensively on the details of specific settings. This raises the challenge of having to significantly reconfigure or redesign the experience for each new location in which it is deployed. Both Uncle Roy All Around You and Can You See Me Now? require extensive work onsite at each new location before they can be played, for example, defining and locating clues, setting start positions for online players and scouting out the performance of technologies such as GPS and $\mathrm{WiFi}$ across the game zone.

- Integrating the physical and the digital: these games demonstrate different approaches to integrating multimedia information with the physical environment including appearing to overlay a virtual world on an existing physical environment, but also using a virtual representation to support periods of reflection between periods of intense physical activity, as we saw in Savannah's Den interface and to some extent in the web archive of photographs in Can You See Me Now?

\section{SCALABLE PERVASIVE GAMES}

While these projects demonstrate the potential to create a variety of richly interactive real-time pervasive gaming experiences, they are limited in one important regard - that of scalability. For each of these experiences, it takes considerable resources, people and technologies, to deliver a game to a relatively few players (typically several hundred street players and a few thousand online players over the course of a couple of weeks for games such as Can You See Me Now? and Uncle Roy All Around You).

There are however some recent examples of more scalable pervasive games for example, I Love Bees, a game in which online media such as the Web are used to set challenges for players who then locate and interact through public payphones [9] and BotFighters!, a commercial game played on mobile phones from the Swedish company Its Alive! [17]. Such games harness the reach of online media and widely deployed devices, including players own mobile phones, to create a structure that can engage thousands of players or more. However, they have yet to deliver the kind of richly interactive real-time experience that can be achieved when the movements of each individual player are tracked in detail through the game zone enabling the game to respond with a highly personalised real-time experience.

In this final section of the paper we therefore consider the challenge of creating future pervasive games that are both richly interactive while at the same time scaling to including potentially very large numbers of players. Specifically, we propose some new approaches that combine pervasive games with online and broadcast services to create nationwide campaigns. A campaign will involve three levels of participation as shown in figure 7:

- The public will upload large volumes of multimedia information from their personal devices using location-based services. These will include pervasive games that capture useful information as a side-effect of play.

- Local-groups including local clubs and societies, activist groups, councils and even schools coordinate local campaign events within a particular locality. They potentially use more specialised technologies to acquire detailed and rigorous multimedia information as part of locally organised events such as school field trips or open days at visitor centres. They communicate with the public and experts using online services.

- Experts and event producers drive and shape the overall campaign at a national or even global level, assimilating multimedia information and feeding it back to the public and local groups through both national, regional and local broadcasting and also online services.

This campaign approach is inspired by recent developments in broadcasting such as online and SMS voting for reality TV shows and also by recent examples of involving the public in environmental campaigns via the web, for example, the BBC's Springwatch campaign that is building a national map of signs of the arrival of Spring as part of an investigation of climate change in the UK [18], and the Royal Society for the Protection of Bird's (RSPB) Big Birdwatch campaign in which members of the public spot birds in their gardens during a specified hour and upload the results into a national database [10]. The campaign model is also 


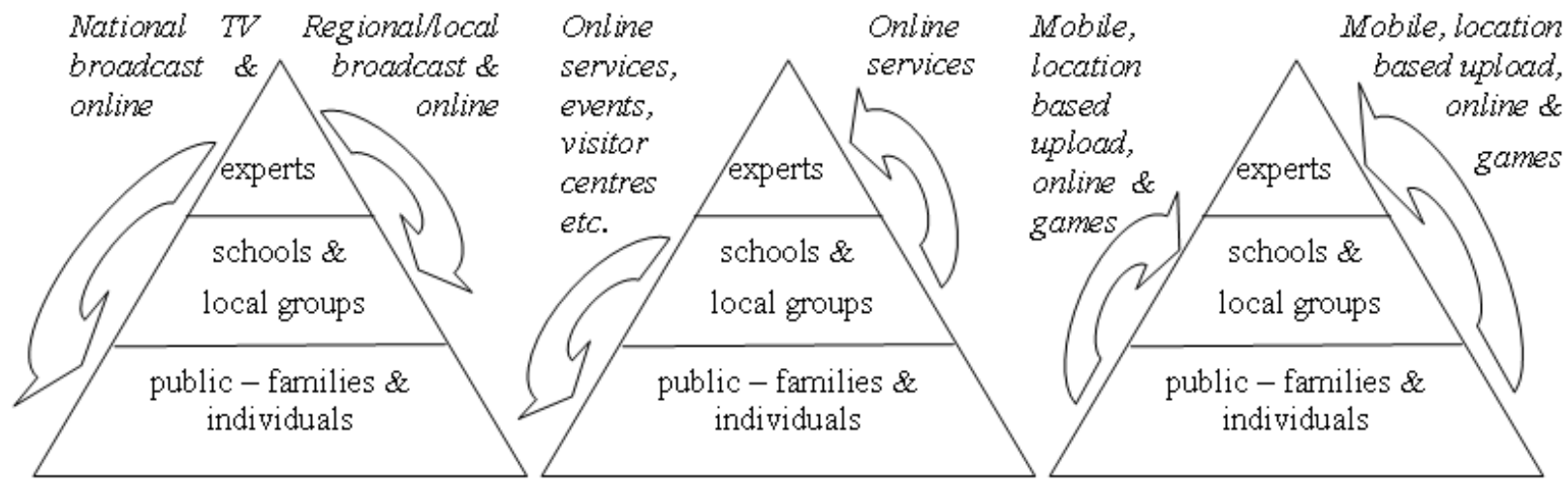

Figure 7. Three layers of participation in a campaign.

inspired by the use of mobile phones to support the spontaneous organization of local events, so-called Flashmobbing. There might be many different kinds of campaigns including environmental monitoring, participation in large-scale TV shows and games, and various forms of local democracy and decision making.

Realising large scale campaigns such as these requires addressing some significant research challenges including: creating pervasive games that also capture useful information; supporting convergence of these pervasive games with online and broadcast media; and realizing new approaches to device and sensor integration. We finish our paper with some initial - as yet untested - proposals for each of these.

\subsection{Pervasive games that capture useful information as a side effect of play}

One important element of our proposed approach is to create pervasive games that motivate individuals to take part in a campaign and that collect useful information as a side effect of play. Early examples of pervasive games that also collect information include Bill, a game that builds up a map of WiFi network coverage as a result of players finding, collecting and depositing virtual coins that are distributed throughout a game zone [19].

Based on this principle, we have recently prototyped a new game for mobile phones that can collect a variety of information from players. In Hitchers, the world is populated by digital characters who are trying to hitch rides on players' mobile phones. Players can create hitchers and release them into the wild. This includes giving them a task such as asking a specific question or inviting people to take a digital photograph using a camera phone.

Players can scan their current phone cell for hitchers and can chose to give a lift to any hitcher that they find. The hitcher will then journey with them until either the players chooses to set it down again or perhaps until it has passed through a specific number of cells. As they go, the hitcher collects various kinds of information including the name of the player, the names of the locations where it was picked up and set down and also of course, the answer to its specific question of task.

We anticipate that this basic framework can provide players with a lightweight and entertaining but also scalable game that they can play on journeys across the country. However, hitchers also collect a variety of information about the people and locations that they encounter including the structure of the cellular network in terms of the topology of its interconnected cells. The Hitchers game therefore includes online interfaces that enable players to view this information as the hitcher moves across the country. The original creator of a hitcher, and possibly other players who have given it a ride, can go online to explore the history of its encounters and view the information that it has collected.

This basic framework could be used to create a variety of games ranging from simple races where points are awarded for the first hitcher to reach a target destination or the hitcher that travels fastest and longest, potentially through to more complex simulation style games in which hitchers are creatures that live in different terrains defined across the cellular network. However, at the same time as supporting different kinds of game play, hitchers can also be though of as information probes that are sent out into the world to capture information - text and possibly photographs - about different locations and to explore the structure of social and technical networks.

\subsection{Convergence of pervasive games with online and broadcast media}

A second element of our proposed approach concerns the convergence of pervasive, online and broadcast media, aiming to exploit the distinctive characteristics of each. Broadcast media provide a powerful way of driving a campaign, stimulating interest and globally coordinating activities, as we see with the previous $\mathrm{BBC}$ and RSPB campaigns mentioned previously. Online media such as the Web provide a way for local groups to coordinate their activities and publish their information. Finally, pervasive media enable players to directly upload information. Indeed, a key feature of the campaign model is that potentially millions of people can provide the underlying content for a large scale experience, distributing the cost of authoring and dealing with the problem of having to configure different content for each location at which it takes place.

\subsection{New approaches to device and sensor integration}

The third element of our approach concerns device integration. At a general level, this campaign model requires the integration of a heterogeneous collection of devices including PCs, consoles, TV, handheld computers, mobile phones and more specialized sensors (e.g., established environmental sensors that may already be 


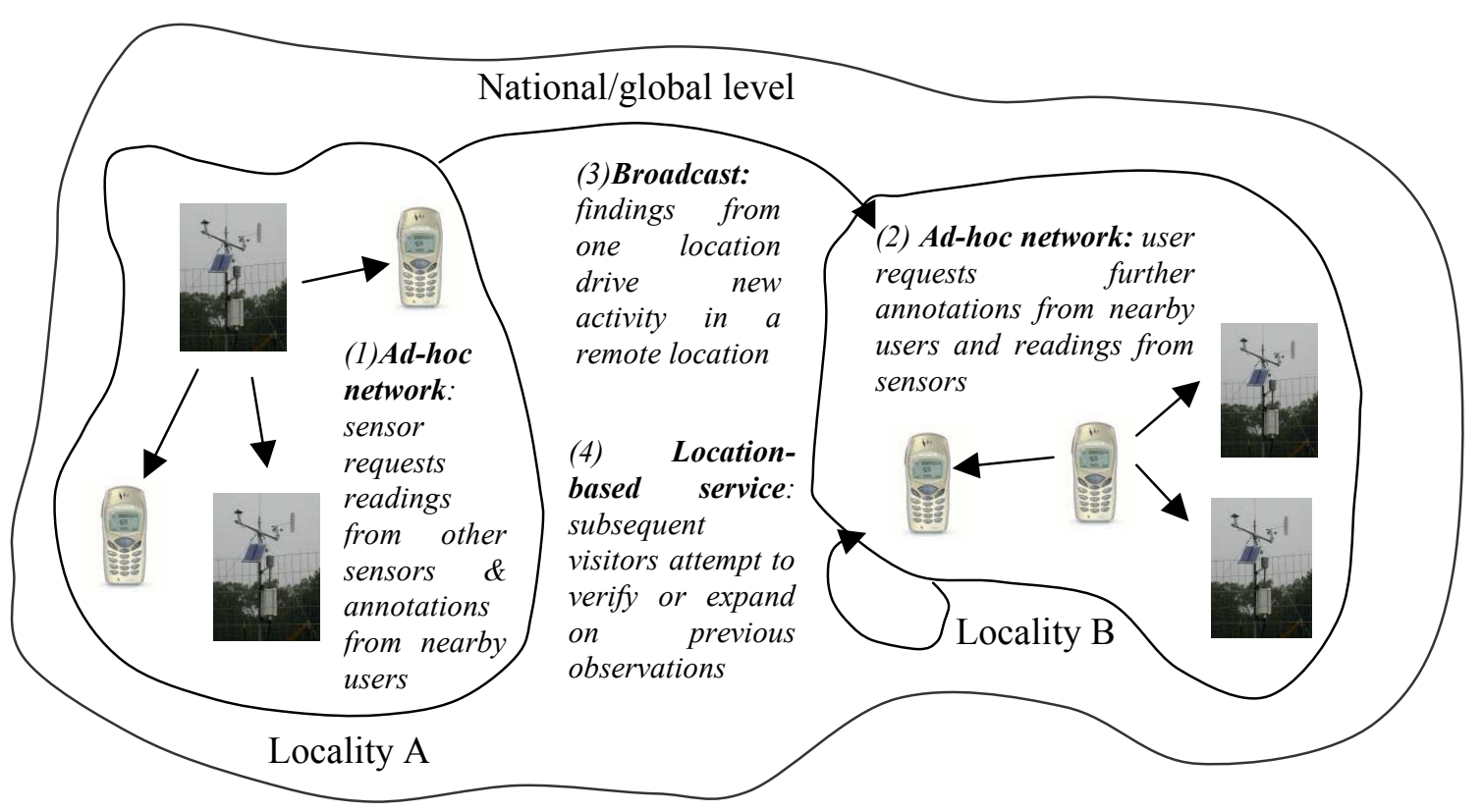

Figure 8. Supporting many users and sensors in a wide-scale pervasive computing.

deployed in some environments). We are especially interested in how mobile players using commodity portable devices such as phones can interact with existing sensors that are embedded in the environment, supported by ad-hoc networking and location-based services, to the benefit of both.

We suggest that there can be four general kinds of interactions between users and sensors as shown in figure 8:

(1) A sensor can request annotations from nearby users, for example requesting the upload of photographs or videos that might help explain an unusual measurement.

(2) Conversely, on observing a potentially significant event, a user can request one or more nearby sensors to record measurements.

(3) Following a significant report, location-based services request passing users by to try to verify it.

(4) Broadcast and online services coordinate activity at a national scale, communicating key observations from one locality to other to see whether similar findings occur elsewhere.

These interactions may be supported by ad-hoc networking in which users' devices contact nearby sensors and other devices or vice versa or by location-based services which detect when devices and sensors are in the same locality (e.g., mobile phone cell) and coordinate their actions accordingly.

In the long term, we envisage scaling up this approach to establish an extensive 'socio-technical sensor network' in which mobile users collaborate with specialised sensors to establish a global picture of environmental conditions.

\section{CONCLUSIONS}

We have discussed the emergence of pervasive games as a new form of multimedia entertainment. We have seen examples of pervasive games that mix mobile and online interaction to create rich experiences in which street players and online players collaborate as part of a game, or alternatively in which street players can review their activities from online later on. We then considered some of the challenges involved in scaling up pervasive games to a national of even level, introducing the idea of a campaign model that combines individual, local group and national levels of participation by integration pervasive gaming with online and broadcast media. We believe that such a model offers great potential to create large-scale mass participation experiences of all kinds and also raises significant new challenges for multimedia research.

As part of our work within the next 18 months, we will move forward to performing trials of large-scale games like Hitchers which will be evaluated through field studies and analysis of system logs. This will be supported by modelling and simulations which use the data from our early trials about patterns of play and interactions between players and sensors in order to predict how the games and supporting technologies could grow to planetary scale.

\section{ACKNOWLEDGEMENTS}

We gratefully acknowledge the support of the Engineering and Physical Sciences Research Council (EPSRC) through the Equator project (www.equator.ac.uk) and also of the Arts and Humanities Research Board (AHRB) and the Arts Council of England (ACE). We would like to acknowledge our collaborators Blast Theory (www.blasttheory.co.uk) for co-developing Can You See Me Now? and Uncle Roy All Around You, as well as the additional support of British Telecom, the BBC and Microsoft Research. We are grateful to Hewlett-Packard, NESTA Futurelab, The BBC and Monks Park School in Bristol for their collaboration on the Savannah project. 


\section{REFERENCES}

[1] R. Want, A. Hopper, V. Falcão, and J. Gibbons, "The active badge location system," in ACM Transactions on Information Systems (TOIS), vol. 10, 1992, pp. 91 102.

[2] R. Want, B. N. Schilit, N. I. Adams, R. Gold, K. Petersen, D. Goldberg, J. R. Ellis, and M. Weiser, "The PARCTAB Ubiquitous Computing Experiment," Xerox Palo Alto Research Center, Palo Alto CSL-95-1, March 1995.

[3] K. Cheverst, N. D., K. Mitchell, A. Friday, and C. Efstratiou, "Developing a context-aware electronic tourist guide: some issues and experiences," presented at SIGCHI conference on Human factors in computing systems, The Hague, The Netherlands, 2000.

[4] P. J. Brown and G. J. F. Jones, "Context-aware retrieval: exploring a new environment for information retrieval and information filtering," in Personal and Ubiquitous Computing, vol. 5, 2001, pp. 253-263.

[5] T. Imielinski and J. C. Navas, "GPS-based geographic addressing, routing, and resource discovery," in Communications of the ACM, vol. 42, 1999, pp. 86 - 92.

[6] S. Benford, D. Rowland, M. Flintham, R. Hull, J. Reid, J. Morrison, K. Facer, and B. Clayton, "Savannah: Designing a location-based game simulating lion behaviour," presented at Proceedings of Conference on Advances in Computer Entertainment 2004, 2004.

[7] S. Benford, C. Magerkurth, and P. Ljungstrand, "Bridging the physical and digital in pervasive gaming," in Communications of the ACM, vol. 48, 2005, pp. 54 57.

[8] W. Piekarski and B. Thomas, "ARQuake: The Outdoors Augmented Reality System," in Communications Of The ACM, vol. 45, 2002, pp. 36-38.

[9] "Ilovebees," in www.ilovebees.com, vol. verified 20th may 2005.

[10] "Birdwatch," in www.rspb.org.uk/birdwatch, vol. verified 20th may 2005 .

[11] "Thegogame," in www.thegogame.com, vol. verified 20th may 2005.
[12] S. Benford, R. Anastasi, M. Flintham, A. Drozd, A. Crabtree, C. Greenhalgh, N. Tandavanitj, M. Adams, and J. Row-Farr, "Coping with uncertainty in a location-based game," in IEEE Pervasive Computing, 2003, pp. 34-41.

[13] Blast Theory, "Can You See Me Now?," in http://www.blasttheory.co.uk/bt/work cysmn.html, vol. 2005. London - UK, 2005.

[14] S. Benford, M. Flintham, A. Drozd, R. Anastasi, D. Rowland, N. Tandavanitj, M. Adams, J. Row-Farr, A. Oldroyd, and J. Sutton, "Uncle Roy All Around You: Implicating the City in a Location-Based Performance," presented at Advanced Computer Entertainment 2004, Singapore, 2004.

[15] S. Benford, W. Seagar, M. Flintham, R. Anastasi, D. Rowland, J. Humble, D. Stanton, J. Bowers, N. Tandavanitj, M. Adams, J. R. Farr, A. Oldroyd, and J. Sutton, "The Error of our Ways: The experience of SelfReported Position in a Location-Based Game," presented at UbiComp 2004, Nottingham - UK, 2004.

[16] S. Benford, D. Rowland, M. Flintham, A. Drozd, R. Hull, J. Reid, J. Morrison, and K. Facer, "Life on the edge: supporting collaboration in location-based experiences," presented at SIGCHI conference on Human factors in computing systems, Portland, Oregon, USA, 2005.

[17] "Botfighters," in www.botfighters.com, vol. verified 20th may 2005.

[18] "Springwatch," in www.bbc.co.uk/nature/animals/wildbritain/springwatch , vol. verified 20th may 2005.

[19] M. Chalmers and A. Galani, "Seamful interweaving: heterogeneity in the theory and design of interactive systems," presented at Designing interactive systems: processes, practices, methods, and techniques, Cambridge, MA, USA, 2004. 